\title{
Auxerre, cathédrale Saint-Étienne. Le suivi scientifique du projet de restauration
}

\section{Christian Sapin}

\section{(2) OpenEdition}

1 Journals

\section{Édition électronique}

URL : https://journals.openedition.org/cem/2922

DOI : $10.4000 /$ cem.2922

ISSN : 1954-3093

Éditeur

Centre d'études médiévales Saint-Germain d'Auxerre

\section{Édition imprimée}

Date de publication : 15 août 2003

ISSN : 1623-5770

\section{Référence électronique}

Christian Sapin, « Auxerre, cathédrale Saint-Étienne. Le suivi scientifique du projet de restauration », Bulletin du centre d'études médiévales d'Auxerre | BUCEMA [En ligne], 7 | 2003, mis en ligne le 05

décembre 2007, consulté le 22 septembre 2022. URL : http://journals.openedition.org/cem/2922 ; DOl : https://doi.org/10.4000/cem.2922

Ce document a été généré automatiquement le 22 septembre 2022.

\section{cc) (†) (5)}

Creative Commons - Attribution - Pas d'Utilisation Commerciale - Partage dans les Mêmes Conditions 4.0 International - CC BY-NC-SA 4.0

https://creativecommons.org/licenses/by-nc-sa/4.0/ 


\title{
Auxerre, cathédrale Saint-Étienne. Le suivi scientifique du projet de restauration
}

\author{
Christian Sapin
}

1 Le grand projet de restauration de la cathédrale d'Auxerre a incité le Centre d'études médiévales d'Auxerre à proposer plusieurs types de suivis scientifiques de l'opération.

- Un conseil scientifique permanent destiné à aider les différents partenaires - Architecte, Conservateurs des Monuments historiques, Ville - dans des choix d'avenir pouvant reposer sur une meilleure connaissance du monument. Ce conseil est composé de Denis CAILlEAuX, maître de conférences en Histoire de l'art à l'Université de Bourgogne ; Fabienne JOUBERT, professeur d'Histoire de l'art à l'Université de Paris IV ; Dieter KIMPEL, professeur d'Histoire de l'art et architecture à l'Université de Stuttgart (Allemagne) ; Peter KURMANN, professeur d'Histoire de l'art à l'Université de Fribourg (Suisse) ; Françoise PERROT, directeur de recherche au CNRS ; Christian SAPIN, directeur de recherche au CNRS ; Harry TITUS, professeur d'Histoire de l'art à l'Université de Wake Forest (États-Unis).

- Un suivi archéologique des travaux directement sur le chantier de restauration. C'était le cas jusqu'à la fin du mois de mars pour le remplacement de la couverture de tuiles et d'une partie de la charpente. Notre collègue Sylvain Aumard, en concertation avec Denis Cailleaux, moi-même et les différents intervenants, a pu proposer une méthodologie pour déterminer les types de tuiles médiévales et réaliser des relevés détaillés des parties des charpentes avant restauration (cf. ce volume p. 15-19). Une équipe du laboratoire de dendrochronologie de Besançon a complété les prélèvements faits il y a quelques années.

- Un relevé complet de la façade occidentale avec l'Université de Stuttgart, sous la responsabilité du professeur Kimpel et l'encadrement de Heike Hansen (cf. ce volume p. 21-24).

- Une campagne d'étude archéologique sur l'emplacement de la nef romane et sur la crypte conservée afin d'établir des comparaisons avec les divers chantiers de l'abbatiale SaintGermain (cf. ce volume p. 13-14). 
2 Ces divers programmes conjugués doivent se poursuivre sur plusieurs années et nous en rendrons compte dans le bulletin avant des publications plus importantes.

INDEX

Index géographique : France/Auxerre

Mots-clés : cathédrale, Saint-Etienne d'Auxerre 